\title{
BALANÇO DE MASSA INTEGRADO ENTRE ALTO-FORNO E ESTAÇÃO DE PRÉ-TRATAMENTO DO GUSA*
}

Péricles Guimarães Oliveira Aguiar ${ }^{1}$ Luis Fernando Andrade de Castro ${ }^{2}$

\section{Resumo}

Este trabalho tem como objetivo desenvolver uma ferramenta de planejamento da produção de aço na Aciaria com foco na redução do ferro-gusa solidificado, através do balanço de massa integrado entre os altos-fornos e a estação de Pré-Tratamento do Gusa da Aperam South America. Os estudos mostraram que os balanços de massa elaborados apresentaram um grau de confiança satisfatório quando correlacionados aos dados industriais. O balanço de massa integrado é capaz de prever o melhor mix de produção na Aciaria em função da qualidade e do tipo de rota de refino do ferro-gusa.

Palavras-chave: Balanço de massa; Ferro-Gusa; Dessiliciação; Desfosforação.

\section{INTEGRATED MASS BALANCE BETWEEN THE BLAST FURNACE AND THE PRE-TREATMENT OF HOT METAL}

\begin{abstract}
This work aims to develop a steel production planning tool in Steelmaking focusing on reducing the solidified pig iron, through the integrated mass balance between the blast furnace and the pre-treatment of hot Metal Aperam South America. Studies have shown that the developed mass balance showed a satisfactory degree of confidence when correlated to industrial data. The integrated mass balance is able to predict the best production mix in Steelmaking depending on the quality and type of pig iron refining route.
\end{abstract}

Keywords: Mass balance; Pig Iron; Desiliconization; Dephosphorization.

1 Engenharia de Materiais, Pós-Graduação em Siderurgia, Engenheiro Metalurgista, Controle de processo da Redução, Aperam South America, Timóteo, Minas Gerais.

2 Engenharia Metalúrgica, Doutorado em Engenharia Metalúrgica e de Minas, Professor, Departamento de Engenharia Metalúrgica, Universidade Federal de Minas Gerais, Belo Horizonte, Minas Gerais. 


\section{INTRODUÇÃO}

Na Aperam South America o ferro-gusa produzido é utilizado pela Aciaria para produção dos aços carbono, elétricos e inoxidáveis. O ferro-gusa segue fluxos distintos dentro da planta de acordo com a necessidade de produção da Aciaria, o aço a ser produzido e sua composição química. Planejar a produção do circuito a quente (Alto-Forno e Aciaria) de forma a evitar a solidificação do ferro-gusa, tem sido um desafio diário para as equipes.

Com o objetivo de apresentar uma ferramenta capaz de auxiliar no planejamento da produção em função da produtividade dos altos-fornos (alto-forno $n^{\circ} 1$ e $n^{\circ} 2$ ) e dos tipos de aços a ser produzidos na Aciaria, foi desenvolvido um balanço de massa capaz de integrar as duas áreas, permitindo um planejamento mais eficaz da produção.

O alto-forno do ponto de vista físico-químico é um grande trocador de calor em contracorrente. Os gases quentes ascendentes trocam calor e reduzem as camadas de carga metálica que se deslocam no sentido contrário. Além do fluxo dos gases o alto-forno é um complexo reator químico, envolvendo as fases sólidas, líquidas e gasosas. A produção é uma função da estabilidade operacional, da carga metálica, dos fundentes e dos redutores carregados no alto-forno (GEERDES et al., 2009).

$\mathrm{Na}$ Aciaria, a etapa de Pré-Tratamento do Gusa (PTG) engloba o processo de redução do teor de silício (dessiliciação), fósforo (desfosforação) e enxofre (dessulfuração). O processo de refino pode ser realizado no carro-torpedo ou na panela. A figura 1 apresenta um desenho esquemático de uma estação PTG com refino do ferro-gusa na panela. (KOROS, 1998)

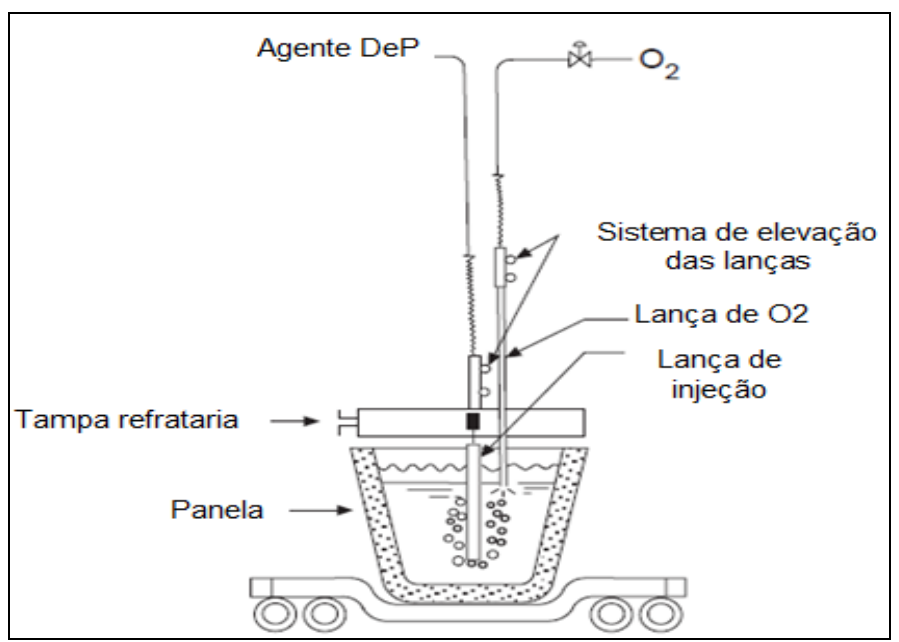

Figura 1. Desenho esquemático de uma estação PTG

O balanço de massa integrado entre os altos-fornos e a etapa de tratamento do ferro-gusa na estação do PTG é dependente da rota seguida pelo ferro-gusa até o convertedor. Essa rota é determina pelo aço a ser produzido, sendo que a rota 1 (dessiliciação - DeSi) é utilizada para produção dos aços carbono e elétricos e a rota 2 (dessiliciação e desfosforação - DeP) para produção dos aços inoxidáveis. A figura 2 apresenta as duas possíveis rotas do ferro-gusa. 


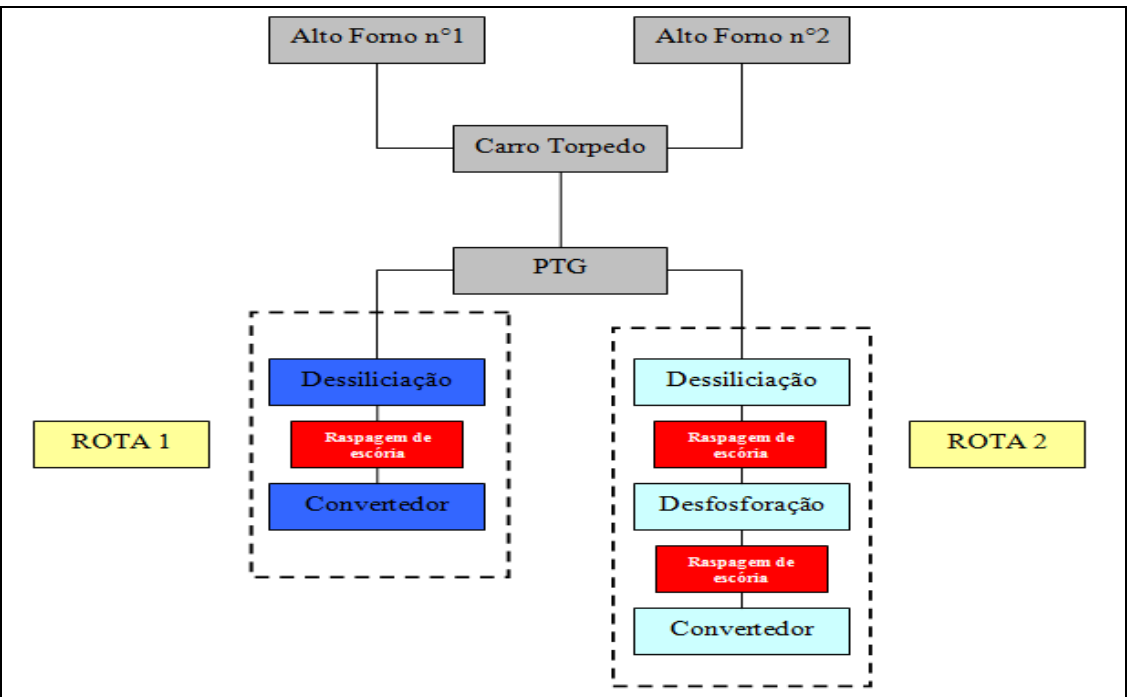

Figura 2. Fluxograma das possíveis rotas do ferro-gusa

\section{MATERIAIS E MÉTODOS}

O desenvolvimento do trabalho engloba três etapas principais: Balanço de massa dos altos-fornos, balanço de massa do PTG e coleta e análises dos dados industriais.

\subsection{Balanço de massa do alto-forno}

O balanço de massa do alto-forno tem como objetivo prever a massa de ferro-gusa e a massa de escória a ser produzido em função da carga carregada no alto-forno. $O$ balanço de massa do ferro (Mfe) e o balanço de massa da sílica $\left(\mathrm{MSiO}_{2}\right)$ são as referências para a realização dos cálculos. A equação (1) apresenta o balanço de massa do ferro e a equação (2) o balanço de massa da sílica.

$$
\begin{aligned}
& \sum M f e_{\text {entrada }}=\sum M f e_{\text {saida }} \\
& \sum M S i O_{2 \text { entrada }}=\sum M S i O_{2 \text { saida }}
\end{aligned}
$$

A tabela 1 apresenta as entradas e saídas de ferro e sílica do alto-forno.

\begin{tabular}{c|c}
$\begin{array}{c}\text { Tabela 1. Entradas e saídas de ferro do alto-forno } \\
\text { ENTRADA }\end{array}$ & SAÍDA \\
\hline Pelota & Ferro-Gusa \\
\hline Minério & Escória \\
\hline Sucata & Pó de Coletor \\
\hline Fundentes & Lama \\
\hline Cinzas (carvão vegetal e/ou coque) & - \\
\hline
\end{tabular}




\subsection{Balanço de massa do Pré-Tratamento do Gusa (PTG)}

O balanço de massa da rota 1 contempla a etapa de dessiliciação. As entradas e saídas de ferro estão apresentadas na tabela 2.

Tabela 2. Entradas e saídas de ferro da rota 1

ENTRADA DE FERRO

\begin{tabular}{c|c}
\hline Ferro-Gusa & Ferro-Gusa DeSi \\
\hline Carepa de Laminação & Escória \\
\hline
\end{tabular}

Conforme a metodologia adotada para cálculo do balanço de massa do ferro no altoforno, a equação (1) representa o balanço de massa do ferro-gusa dessiliciado. As reações de (3) e (4) apresentam a oxidação do silício (Si) e manganês (Mn) dissolvidos no ferro-gusa pelo oxido de ferro (FeO) presente na carepa de laminação.

$$
\begin{aligned}
& \underline{\mathrm{Si}}+2 \mathrm{FeO}_{(s)}=2 \underline{\mathrm{Fe}}+\mathrm{SiO}_{2(l)} \\
& \underline{\mathrm{Mn}}+\mathrm{FeO}_{(s)}=\underline{\mathrm{Fe}}+\mathrm{MnO}_{(l)}
\end{aligned}
$$

O balanço de massa da rota 2 contempla a etapa de dessiliciação e desfosforação, onde as entradas e saídas de ferro estão apresentadas na tabela 3.

Tabela 3. Entradas e saídas de ferro da rota 2

\begin{tabular}{c|c}
\hline ENTRADA DE FERRO & SAÍDA DE FERRO \\
Ferro-Gusa DeSi & Ferro-Gusa DeP \\
\hline Carepa de Laminação & Escória \\
\hline Agente Desfosforante & - \\
\hline
\end{tabular}

A primeira etapa da rota 2 é a dessiliciação do ferro-gusa pela carepa de laminação conforme a rota 1 . Na segunda etapa o agente desfosforante rico em minério de ferro e cálcio é injetado no ferro-gusa reduzindo os teores de silício, manganês e fósforo. As reações de (5) a (8) apresentam a oxidação desses elementos. A oxidação do carbono ocorre pelo oxigênio soprado simultaneamente com a injeção do agente desfosforante. As reações (9) e (10) apresentam a oxidação do carbono.

$$
\begin{aligned}
& \underline{3 \mathrm{Si}}+2 \mathrm{Fe}_{2} \mathrm{O}_{3(s)}=4 \underline{\mathrm{Fe}}+3 \mathrm{SiO}_{2(l)} \\
& \underline{3 \mathrm{Mn}}+\mathrm{Fe}_{2} \mathrm{O}_{3(s)}=2 \underline{\mathrm{Fe}}+3 \mathrm{MnO}_{(l)} \\
& 3 \underline{P}+5 / 2 \mathrm{Fe}_{2} \mathrm{O}_{3(s)}=5 \underline{\mathrm{Fe}}+3 / 2 \mathrm{P}_{2} \mathrm{O}_{5(l)} \\
& \mathrm{P}_{2} \mathrm{O}_{5(l)}+4 \mathrm{CaO} \mathrm{O}_{(s)}=4 \mathrm{CaO} \cdot \mathrm{P}_{2} \mathrm{O}_{5(l)} \\
& \underline{\mathrm{C}}+1 / 2 \mathrm{O}_{2(g)}=\mathrm{CO}_{g} \\
& \underline{\mathrm{C}}+\mathrm{O}_{2(g)}=\mathrm{CO}_{2(g)}
\end{aligned}
$$




\subsection{Coleta e análise dos dados industriais}

Os dados foram coletados durante o período de janeiro de 2015 a março de 2016 . O cálculo do balanço de massa foi realizado mensalmente, utilizando as médias de análise química das cargas, escória e ferro-gusa.

Para análise dos dados industriais foi utilizado o Office Excel.

\section{RESULTADOS E DISCUSSÃO}

\subsection{Validação do cálculo da produção pelo balanço de massa do alto-forno}

Com o objetivo de validar o balanço de massa desenvolvido para cálculo da produção de ferro-gusa pelos altos-fornos, comparou-se a produção calculada pelo SIP (Sistema de Informação de Processo) com a produção calculada pelo balanço de massa (B.M). A pequena variação no valor da produção se deve ao fato do SIP trabalhar com média diária da análise química e umidade dos materiais enfornados. Enquanto que no cálculo da produção pelo balanço de massa foi utilizada a média mensal. A correlação entre os dois cálculos da produção apresentou um $R^{2}=0,985$ como mostra a figura 2, validando o balanço de massa com um grau satisfatório de confiança.

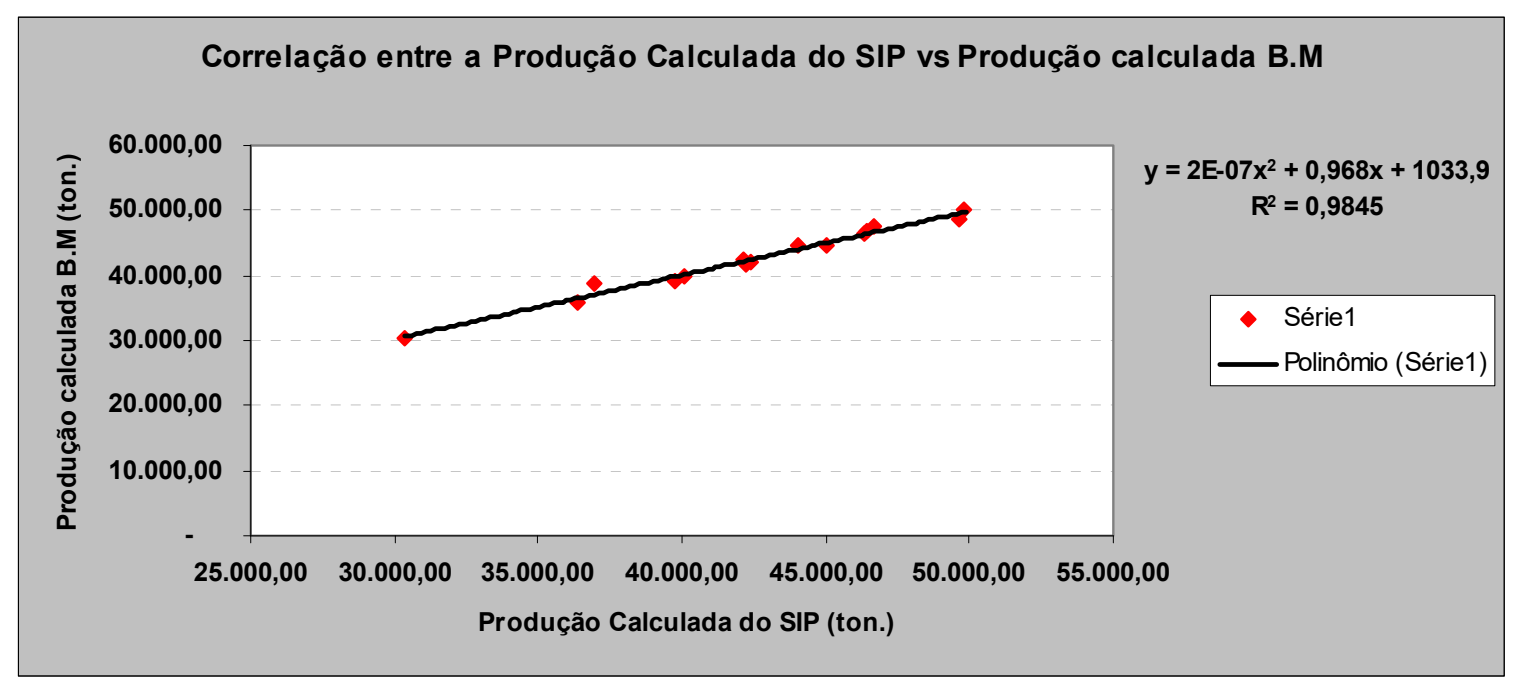

Figura 2. Correlação entre a produção calculada do SIP e a produção calculada pelo balanço de massa.

\subsection{Influência do teor de silício do ferro-gusa no processo PTG}

De acordo com (KOROS, 1998) o silício funciona como bloqueio para oxidação do fósforo, por apresentar maior afinidade pelo oxigênio. Conforme apresentado na figura 3, a desfosforação começa quando o teor de silício atinge valores abaixo de $0,15 \%$. 


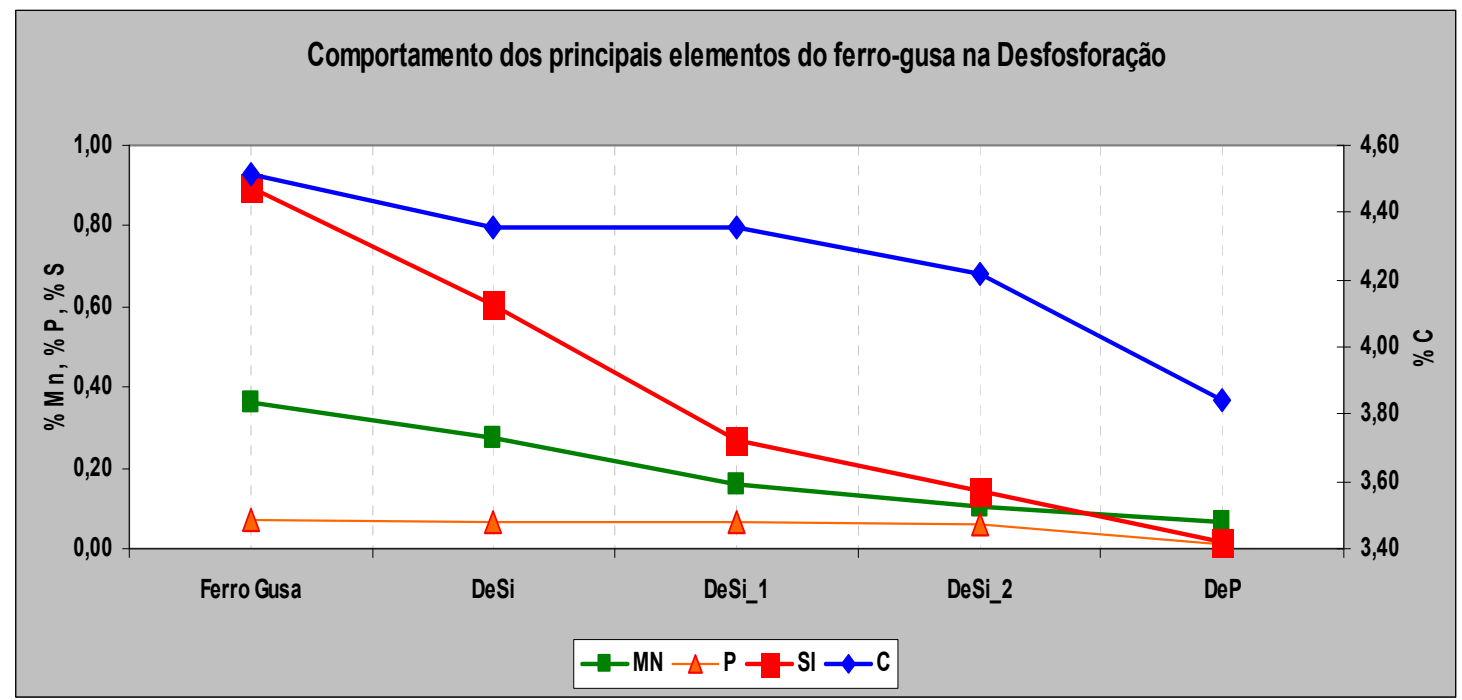

Figura 3. Comportamento do carbono, silício, manganês e fósforo durante a etapa de desfosforação.

Quanto maior for o teor do silício inicial (percentual de silício no ferro-gusa), maior o teor de silício após a etapa de dessiliciação. A figura 4 apresenta a relação entre o teor de silício do ferro-gusa e o teor de silício após a etapa DeSi.

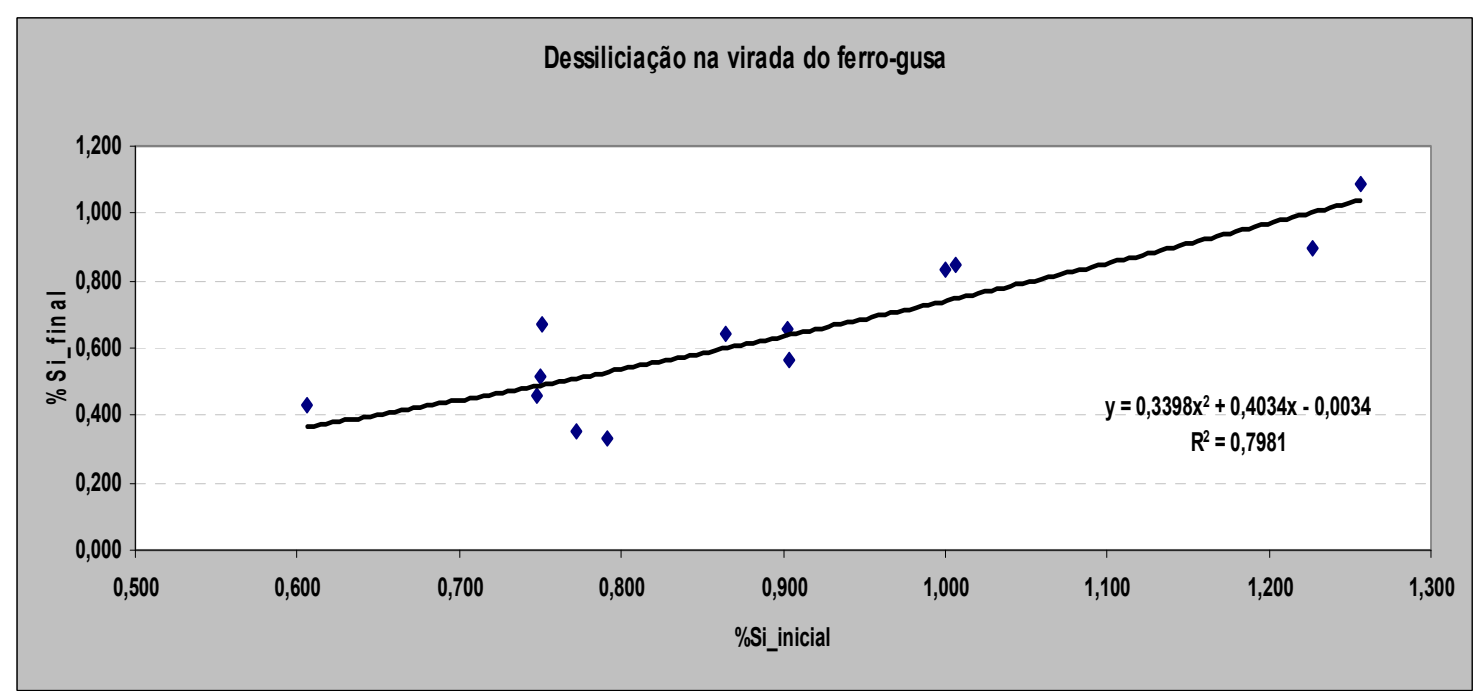

Figura 4. Correlação entre o teor de silício do ferro-gusa e o teor de silício após a etapa de DeSi.

O aumento no teor do silício após a etapa DeSi impacta diretamente no consumo do agente DeP, aumentando o custo do ferro-gusa tratado e o tempo de processamento. A tabela 4 apresenta o impacto do percentual de silício no consumo de agente desfosforante e no tempo de processamento. 
Tabela 4. Impacto do \%Si do ferro-gusa no consumo de agente DeP e no tempo de tratamento.

\begin{tabular}{cccc}
\hline \%Si Ferro-Gusa & \%Si_DeP & Consumo Agente DeP (kg/t) & Tempo Tratamento DeP (min) \\
\hline 0,40 & 0,011 & 28,88 & 51,77 \\
\hline 0,50 & 0,038 & 29,05 & 57,46 \\
\hline 0,60 & 0,063 & 29,88 & 63,53 \\
\hline 0,70 & 0,088 & 31,24 & 69,99 \\
\hline 0,80 & 0,110 & 33,03 & 76,82 \\
\hline 0,90 & 0,131 & 35,16 & 84,04 \\
\hline 1,00 & 0,151 & 37,51 & 91,64 \\
\hline 1,10 & 0,169 & 40,01 & 99,63 \\
\hline 1,20 & 0,185 & 42,57 & 107,99
\end{tabular}

\subsection{Validação do cálculo da produção pelo balanço de massa do PTG}

Com o objetivo de validar o balanço de massa desenvolvido para cálculo da produção de ferro-gusa após a etapa do PTG, comparou-se a massa de ferro-gusa pesada na entrada dos convertedores com a massa de ferro-gusa determinada pelo balanço de massa da Rota 1 e Rota 2 . A variação no valor da massa de ferro-gusa se deve às perdas de massa durante a raspagem de escória e a perda de carepa para o sistema de desempoeiramento. A correlação entre as duas massas apresentou um $\mathrm{R}^{2}=0,987$ como mostra a figura 5 , validando o balanço de massa com um grau satisfatório de confiança.

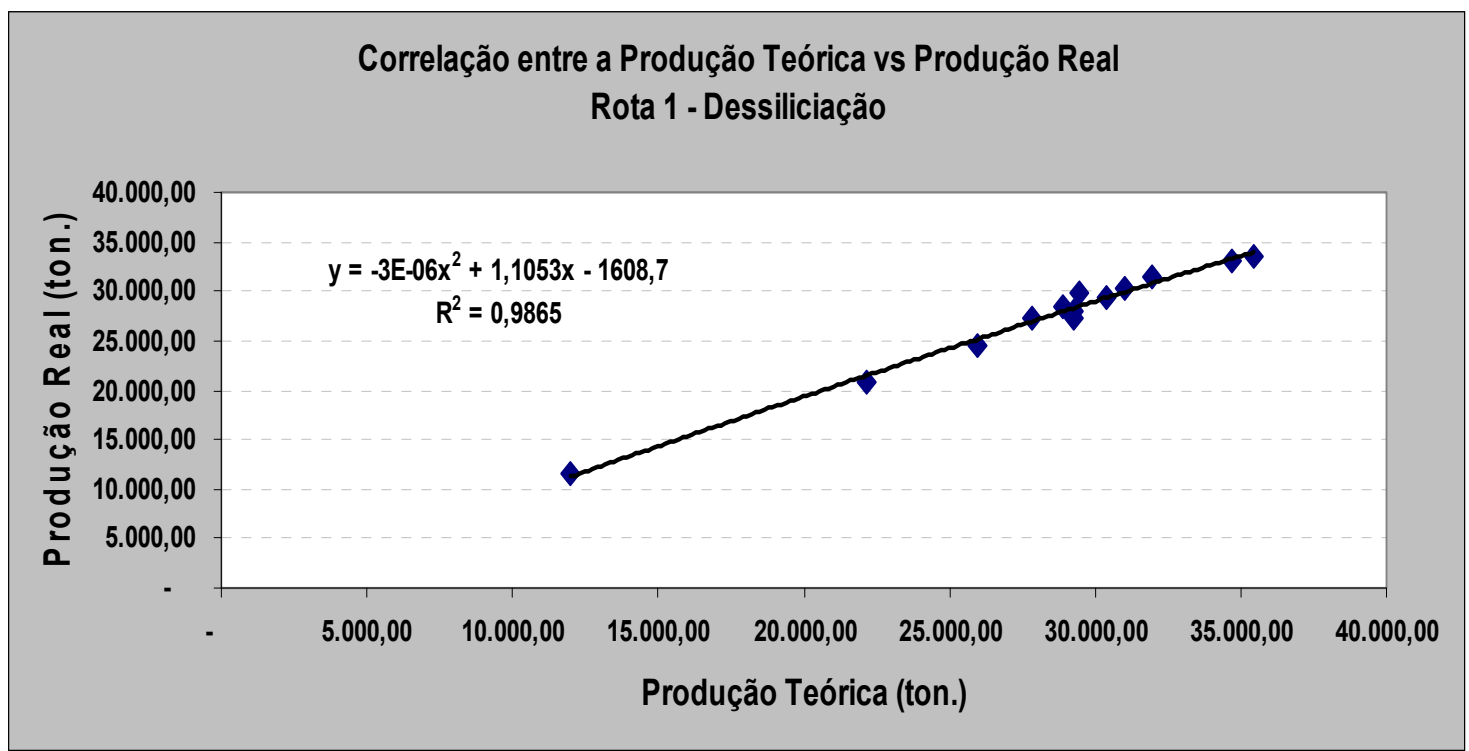

Figura 5. Correlação entre a massa de ferro-gusa pesado na entrada do convertedor e a massa de ferro-gusa calculada pelo balanço de massa da Rota 1.

Para validação da Rota 2, foi aplicada a mesma análise da rota 1 . A variação no valor da massa de ferro-gusa se deve às perdas de massa durante a raspagem de escória, perda de carepa e agente desfosforante para o sistema de desempoeiramento e vazamentos no circuito de injeção. A correlação entre as duas massas apresentou um $\mathrm{R}^{2}=0,987$ como mostra a figura 6 , validando o balanço de massa com um grau satisfatório de confiança. 


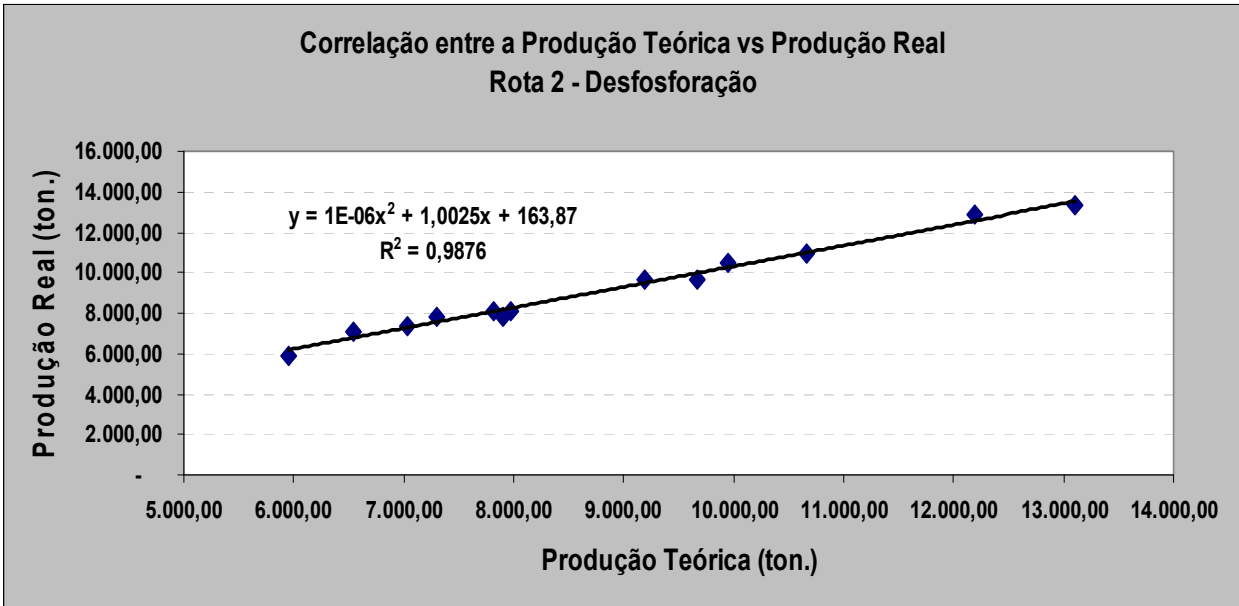

Figura 6. Correlação entre a massa de ferro-gusa pesado na entrada do convertedor e a massa de ferro-gusa calculada pelo balanço de massa da Rota 2.

\subsection{Aplicação do balanço de massa integrado Alto-Forno e PTG}

O balanço de massa integrado é aplicado para prever:

- massa de ferro-gusa disponível para o PTG;

- massa de ferro-gusa a ser solidificado;

- capacidade de processamento do PTG;

- tempo de processamento da DeP;

- consumo de agente DeP;

A figura 7 apresenta exemplos da aplicação do balanço de massa em função da produção diária dos altos-fornos e a qualidade do ferro-gusa. Onde a figura (a) apresenta o balanço de massa aplicado à produção mista entre a Rota $1(70 \%)$ e Rota $2(30 \%)$, a capacidade de processamento do PTG é superior a massa necessária de ferro-gusa tratado, não sendo necessária a solidificação do ferrogusa. Na figura (b) $100 \%$ do ferro-gusa segue a Rota 2, excedendo a capacidade de processamento do PTG e solidificando 508,32 toneladas de ferro-gusa.
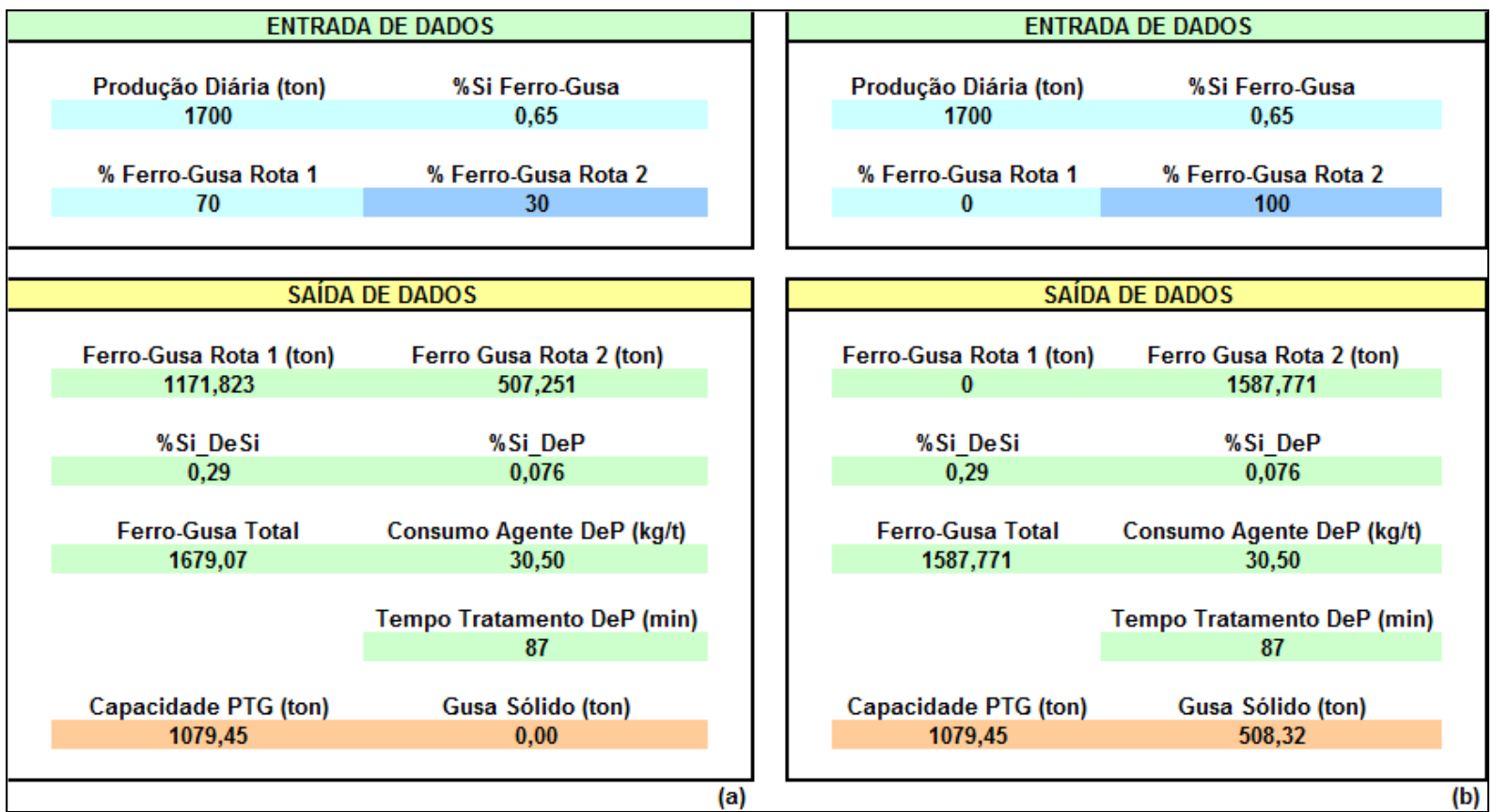

Figura 7 - Aplicação do balanço de massa integrado. 


\section{CONCLUSÃO}

As correlações apresentadas pelos balanços de massa indicaram um grau de confiança satisfatório.

O controle do percentual do silício dissolvido no ferro-gusa é fundamental para atingir o máximo da capacidade de processamento do PTG com o menor consumo de agente DeP.

O planejamento da produção equilibrando o mix de produção entre as Rotas 1 e 2 permite absorver a produção total de ferro-gusa dos altos-fornos evitando solidificar parte da produção.

\section{Agradecimentos}

Os autores agradecem a empresa Aperam South America, a Universidade Federal de Minas Gerais (UFMG), ao Programa de Pós-Graduação em Engenharia Metalúrgica, Materiais e de Minas (PPGEM) e a CAPES/ PROEX.

\section{REFERÊNCIAS}

1 Geerds M, Toxopeus H, Vliet CVD. Modern Blast Furnace Ironmaking an introduction. $2^{a}$ edição. Amsterdam: IOS Press BV; 2009.

2 Koros PJ, In: SteelMaking and Refining Volume. Capther 7: Pret-Treatment of Hot Metal. Pittsburgh: The AISE Steel Foundation; 1998. p. 413-429. 